\title{
КЛАССИФИКАЦИЯ ВОЗМОЖНЫХ НАРУШЕНИЙ ПРИ РАСХОДОВАНИИ СРЕДСТВ НА ФЕДЕРАЛЬНЫЕ ПРОЕКТЫ
}

\author{
(C) 2021 Петров Александр Михайлович \\ доктор экономических наук, профессор Департамента бизнес-аналитики \\ Финансовый университет при Правительстве Российской Федерации, Россия, Москва \\ профессор кафедры бухгалтерского учета и налогообложения \\ Российский экономический университет им. Г. В. Плеханова, Россия, Москва \\ E-mail:palmi@inbox.ru
}

В статье на основе ранжирования возможных нарушений при расходовании средств на федеральные проекты, исследованы подходы к оценке отраслевых рисков и разработана система индикаторов оценки отраслевых рисков в процессе расходования средств. Обусловлена необходимость применения различных методов оценки риска в практике деятельности субъектов хозяйствования и дана характеристика их возможного применения. Дана собственная точка зрения на методы управления рисками, формирование системы индикаторов и процесс отбора ключевых индикаторов риска. Выявлены принципы эффективного формирования ключевых индикаторов риска.

Ключевые слова: бюджетные нарушения, федеральный проект, отраслевой риск, ключевые индикаторы риска.

Нарушения в части расходования средств на федеральные проекты могут быть классифицированы по нескольким признакам: наличию системности в их совершении; тенденции к снижению или увеличению (как в сравнении с прошлыми периодами, так и относительно иных нарушений); по объектам проверок (участники бюджетного процесса, бюджетные учреждения, автономные учреждения, коммерческие и некоммерческие субъекты хозяйствования, использующие полученные бюджетные средства).

Также нарушения в части расходования средств на федеральные проекты могут быть классифицированы по последствиям для бюджета (безрезультатное расходование (отвлечение), избыточное расходование, длительное неиспользование бюджетных средств).

Рассматривая вопрос ранжирования возможных нарушений в части расходования средств на федеральные проекты, можно провести аналогию с концепцией миофасциального болевого синдрома, под которым понимается чрезмерная чувствительность мышц, «которая может в значительной степени модулировать функции центральной нервной системы» [6].

Джанет Г.Трэвелл и Дэвид Г.Симонс выделяли две классификационные группы миофасциальных триггерных точек (триггерных зон, триггерных областей), способных оказывать влияние на состояние системы (в данном случае центральной нервной системы), представленные на рисунке 1.

Трансформируя данные рисунка 1 на рассматриваемую область исследования (рисунок 2), используя прием аналогии, можно прийти к выводу, что несвоевременный контроль расходования средств на отдельные федеральные проекты, в том числе региональные проекты, может привести к недостижению целевых показателей, как отдельных федеральных проектов, так и национальных проектов, частью которых они являются, приводя к сбоям или нарушению функционирования системы расходования и контроля средств в стране в целом.

На основании вышеуказанного предлагается следующее ранжирование возможных нарушений при расходовании средств на федеральные бюджеты:

1. Активное (нарушение расходования средств в крупных размерах или по целевым показателям, приводящее к угрозе невозможности реализации запланированных федеральных проектов или необходимости дополнительного расходования средств).

2. Латентное (нарушение расходования средств в малых размерах или по сопутствующим направлениям, необходимым для достижения целевых показателей, способное замедлять процесс реализации запланированных федеральных проектов, которое может быть обнару- 


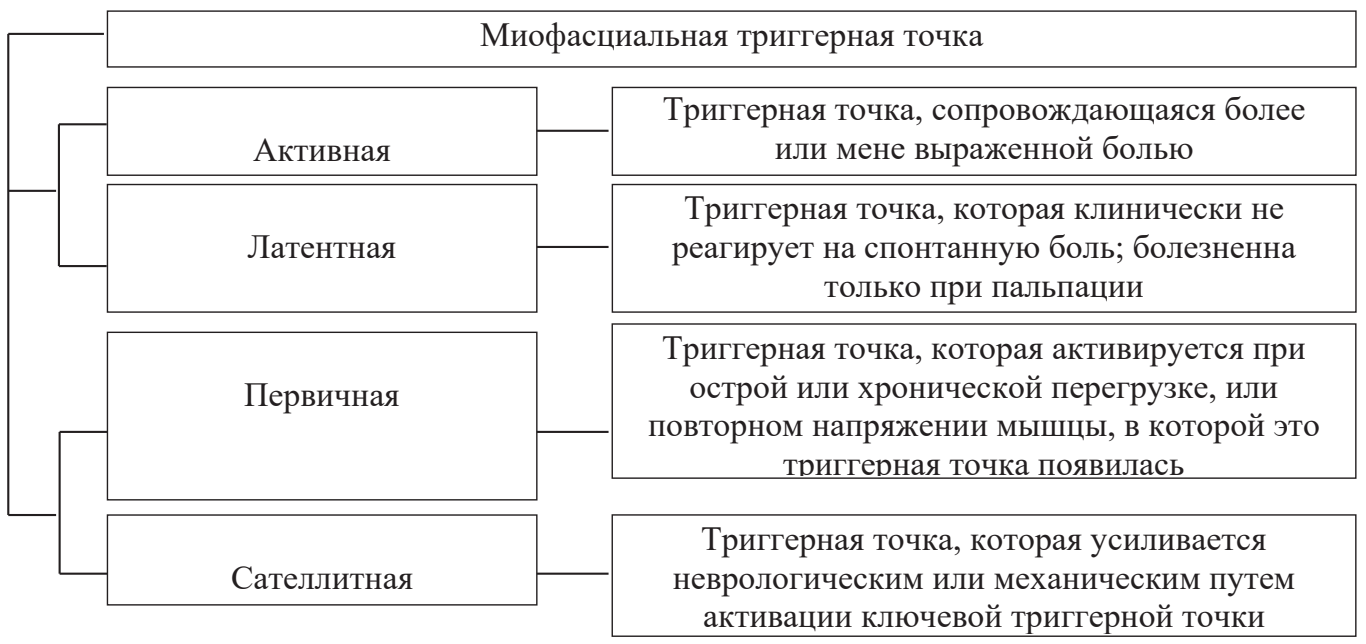

Рисунок 2. Классификация миофасциальных триггерных точек Источник: составлено по материалам [6].

жено только при проведении целенаправленной проверки).

3. Первичное (нарушение, которое возникает в случае привлечения большого внимания либо выделения больших объемов финансирования на достижение определенных целевых показателей).

4. Сателлитное (нарушение, которое возникает при переключении внимания на достижение иных целевых показателей либо обусловлено им, сопровождаемое ослаблением контроля).

В конце статьи представлена система индикаторов оценки рисков, учитывающая риски по сфере возникновения и риски, отражающие отраслевую специфику в процессе расходования средств на федеральные проекты в Российской Федерации.

В статье проведено ранжирование возможных нарушений при расходовании средств на федеральные проекты, исследованы подходы к оценке отраслевых рисков и разработана система индикаторов оценки отраслевых рисков в процессе расходования средств. Обусловлена необходимость применения различных методов оценки риска в практике деятельности субъектов хозяйствования и дана характеристика их возможного применения. В исследовании дана собственная точка зрения на методы управления рисками, формирование системы индикаторов и процесс отбора ключевых индикаторов риска. Выявлены принципы эффективного формирования ключевых индикаторов риска.

\section{Система индикаторов оценки рисков}

А. Классификация рисков по сфере возникновения:

I. Экзогенные риски:

* Стратегические воздействия рыночного риска, включая:

- Рынок акций падает, сокращая объемы продаж инвестиций и пенсионных переводов, но увеличивая спрос на другие типы фондов;

- Изменения базовой ставки влияют на привлекательность вкладов для других сберегательных продуктов;

- Изменения доходности среднесрочных облигаций, влияющие на условия структурированных продуктов и ипотечные сделки с фиксированной ставкой;

- Изменения волатильности капитала также влияют на условия структурированных продуктов;

- Цены на жилую недвижимость и арендная плата, влияющие на привлекательность сдачи в аренду, но при этом также влияют на средний размер случаев защиты по ипотеке;

* Макроэкономический риск, связанный с влиянием макроэкономических воздействий, оказывающих негативное влияние на новый бизнес и стратегию развития бизнеса:

- Изменение объемов ипотечного кредитования;

- Безработица, влияющая на спрос на продукцию;

* Стратегические последствия кредитного риска - связанные с изменениями в кредитном опыте, влияющими на будущую прибыльность 


\begin{tabular}{|c|c|}
\hline \multicolumn{2}{|c|}{ Нарушение в части расходования средств на федеральные проекты } \\
\hline Активное & $\begin{array}{l}\text { Нарушение расходования средств в крупных размерах или по } \\
\text { целевым показателям, приводящее к угрозе невозможности } \\
\text { реализации запланированных федеральных проектов или } \\
\text { необходимости дополнительного расходования средств }\end{array}$ \\
\hline Латентное & $\begin{array}{l}\text { Нарушение расходования средств в малых размерах или по } \\
\text { сопутствующим направлениям, необходимым для достижения } \\
\text { целевых показателей, способное замедлять процесс реализации } \\
\text { запланированных федеральных проектов, которое может быть } \\
\text { обнаружено только при проведении целенаправленной проверки }\end{array}$ \\
\hline Первичное & $\begin{array}{l}\text { Нарушение, которое возникает в случае привлечения большого } \\
\text { внимания либо выделения больших объемов финансирования } \\
\text { на достижение определенных целевых показателей }\end{array}$ \\
\hline Сателлитное & $\begin{array}{l}\text { Нарушение, которое возникает при переключении внимания на } \\
\text { достижение иных целевых показателей либо обусловлено им, } \\
\text { сопровождаемое ослаблением контроля }\end{array}$ \\
\hline
\end{tabular}

Рисунок 3. Классификация нарушений в части расходования средств на федеральные проекты, основанная на классификации миофасциальных триггерных точек

нового бизнеса и общую стратегию развития бизнеса (хотя переоценка цен может смягчить это).

Стратегические последствия страхового риска - связанные с изменениями уровней устойчивости и другим опытом, влияющим на будущую прибыльность нового бизнеса и общую стратегию (то же самое).

* Фискальный риск, связанный с изменениями в налогообложении:

- Изменения в налогообложении продукции, влияющие на спрос на нее;

- Общая налоговая нагрузка, влияющая на спрос на продукцию;

* Политический риск - риск того, что политическая неопределенность влияет на спрос на продукцию.

* Регуляторный риск - для продаж и деловой репутации:

- Влияние на распространение продуктов;

- Регулирование самих продуктов, например, ограничение цен для заинтересованных сторон;

* Риск демографических и социальных изменений - риск того, что общие демографические и социальные изменения (например, использование Интернета или увеличение числа случаев досрочного выхода на пенсию) будут отличаться от ожидаемых в стратегии или что тенденции не будут определены в первую очередь.

* Риск тенденций товарных рынков - риск неспособности должным образом предвидеть рыночные тенденции товарных рынков (например, рост числа «закрытых» платформ отличается от ожидаемого).

* Риски конкурентов:

- влияние на продажи цен конкурентов;

- влияние на каналы сбыта действий конкурентов;

* Риск распространения - риск сокращения объемов продаж, поступающих через каналы сбыта (например, сокращение числа консультантов у ключевых дистрибьюторов или неплатежеспособность дистрибьютора). Включает риск ухудшения отношений с дистрибьюторами.

* Риски поставщика продуктов - риск, исходящий от поставщиков, продукция которых лежат в основе стратегии реализации проекта, например, риск того, что договора будут расторгнуты или условия станут менее привлекательными. Включает зависимость страховщиков от перестраховщиков и риск того, что более жесткие условия перестрахования отрицательно повлияют на продажи и / или маржу.

\section{II Эндогенные риски:}

* Риск продукта - риск того, что продукция недостаточно привлекательна для удовлетворения потребностей целевого рынка; или что маржа недостаточна для достижения целей рентабельности.

\footnotetext{
* Риск обслуживания - покрывает не
} 
только неадекватное обслуживание, не отвечающее ожиданиям целевого рынка, но и несоответствующие модели обслуживания.

* Риск бренда и репутации - плохая репутация подрывает стратегию или бренд фирмы не поддерживает стратегические цели:

- Репутационный ущерб от операционных ошибок, таких как неправильная продажа;

- Опасения по поводу финансовой устойчивости (из-за рыночных и других событий);

- Бренд, не поддерживающий стратегию;

* Риск проекта - риск того, что проект потерпит неудачу. Включает сбои проектов по:

- улучшению / устранению «пробелов» в предложениях продуктов и услуг;

- сокращению расходов;

- снижению портфельного рисков;

* Риск возможности ценообразования связан с неспособностью эффективно конкурировать из-за отсутствия:

- анализа методов ценообразования про- дуктов; и / или

- данных для эффективного ценообразования продуктов на рынке.

* Риск IT-систем - связан с тем, что IT-системы не могут поддерживать разработку продукта и другие стратегические цели; или что новые бизнес-системы не работают, что ставит под угрозу продажи.

* Риск планирования и предположений связан с плохим планированием, включая ошибочные предположения. Также включает неблагоприятные отклонения в профилях тех, кто покупает новые продукты от ожидаемых.

* Риск первоначальных расходов - первоначальные затраты выше ожидаемых, что снижает прибыльность реализации проекта.

* Риск капитала - что у фирмы недостаточно капитала для реализации своей стратегии, или что новые объемы бизнеса, превышающие ожидаемые, отрицательно влияют на финансовую устойчивость.

Б) Классификация рисков, отражающих отраслевую специфику в процессе расходования средств на федеральные проекты в Российской Федерации:

\begin{tabular}{|c|c|}
\hline Структурные риски & $\begin{array}{l}\text { - Барьеры вхождения в отрасль } \\
\text { - Степень ценовой и неценовой конкуренции } \\
\text { - Наличие или недостаток близких и конкурентоспособных по цене заменителей } \\
\text { - Уровень государственной поддержки } \\
\text { - Экспортный потенциал отрасли } \\
\text { - Импортный потенциал отрасли } \\
\text { · Жизненный цикл отрасли - стадия жизненного цикла, в которой находится от- } \\
\text { расль: рост, зрелость, упадок (низкий балл для роста, высокий балл для спада) } \\
\text { · Волатильность отрасли - уровень нестабильности доходов в отрасли за последние } \\
5 \text { лет. }\end{array}$ \\
\hline Экономические риски & $\begin{array}{l}\text { · Риск возрастания сметной стоимости проекта } \\
\text { - Процентный риск } \\
\text { · Валютный риск } \\
\text { · Инфляционный риск } \\
\text { · Риск рефинансирования }\end{array}$ \\
\hline Управленческие риски & $\begin{array}{l}\text { - Падение объемов сбыта продукции } \\
\text { · Риск замены партнера } \\
\text { · Риск повышения эксплуатационных затрат } \\
\text { · Риск возникновения форс-мажорных обстоятельств }\end{array}$ \\
\hline Технологические риски & $\begin{array}{l}\text { · Риск недостаточного уровня технической проработанности проекта } \\
\text { · Риск применения неопробованных технологий } \\
\text { · Инновационный риск (при внедрении более дешевого метода производства това- } \\
\text { ра или услуги по сравнению с уже использующимися, при создании нового товара } \\
\text { или услуги на старом оборудовании, при производстве нового товара или услуги } \\
\text { при помощи новой техники и технологии) } \\
\text { · Риски техногенного и природного характера }\end{array}$ \\
\hline $\begin{array}{l}\text { Информационные } \\
\text { риски }\end{array}$ & $\begin{array}{l}\text { • Риск потерь, возникающих в связи с неполадками в работе компьютерных систем } \\
\text { по обработке информации }\end{array}$ \\
\hline Политические риски & $\begin{array}{l}\text { · Риск изменения приоритетов социально-экономического развития } \\
\text { · Коррупционный риск } \\
\text { · Бюрократический риск }\end{array}$ \\
\hline Правовые риски & $\begin{array}{l}\text { · Риск законодательных изменений } \\
\text { · Повышенная налоговая нагрузка на отрасль } \\
\text { · Риск увеличения налоговой нагрузки }\end{array}$ \\
\hline Экологические риски & \begin{tabular}{|l} 
· Изменчивость климата \\
· Риск загрязнения окружающей среды
\end{tabular} \\
\hline
\end{tabular}




\section{Библиографический список}

1. «Бюджетный кодекс Российской Федерации» от 31.07.1998 № 145-Ф3 (ред. от 01.10.2020)// СПС КонсультантПлюс.

2. «Кодекс Российской Федерации об административных правонарушениях» от 30.12.2001 № 195-Ф3 (ред. от 31.07.2020) (с изм. и доп., вступ. в силу с 11.08.2020) // СПС КонсультантПлюс.

3. «Уголовный кодекс Российской Федерации» от 13.06.1996 № 63-Ф3 (ред. от 31.07.2020) // СПС КонсультантПлюс.

4. Федеральный закон от 05.04.2013 г. № 44-Ф3 «О контрактной системе в сфере закупок товаров, работ, услуг для обеспечения государственных и муниципальных нужд» (в ред. от 27.12.2019 г.) // СПС КонсультантПлюс.

5. Не ростом, так умом. Как национальные проекты повлияют на динамику российской экономики// Российская газета: [сайт]. - 2019. - 14 мая. - Текст: электронный. - URL: https://rg.ru/2019/05/14/kak-nacionalnyeproekty-povliiaiut-na-dinamiku-rossijskoj-ekonomiki.html.

6. Миофасциальные боли и дисфункции: Руководство по триггерным точкам. В 2 томах. Т. 1 // Ж.Г. Трэвелл, Д.Г. Симонс, Л. С. Симонс. - 2-е издание, переработанное и дополненное.- М.: Медицина, 2005. - 1192 с.

7. Россия - страна технооптимистов // Всероссийский центр изучения общественного мнения: [сайт].2019. - 05 февраля. - Текст: электронный. - URL: https://wciom.ru/index.php?id=236\&uid=10151.

8. Chernysheva N.A., Perskaya V.V., Petrov A. M., Bakulina A. A. GREEN ENERGY FOR BELT AND ROAD INITIATIVE: ECONOMIC ASPECTS TODAY AND IN THE FUTURE / International Journal of Energy Economics and Policy. 2019. T. 9. № 5. C. 178-185.

9. Kevorkova Z.A., Petrov A. M., Savina N. V. TOWARDS LIABILITIES OF CORPORATE SYSTEMS / International Journal of Civil Engineering and Technology. 2019. T. 10. № 2. C. 1582-1593.

10. Petrov A.M., Nikiforova E.V., Kiseleva N.P., Grishkina S. N., Lihtarova O.V. CREATION OF THE REPORTING ON SUSTAINABLE DEVELOPMENT OF COMPANIES BASED ON SOCIOECONOMIC MEASUREMENT STATISTICS / International Journal of Recent Technology and Engineering. 2019. T. 8. № 2. C. 4005-4012.

11. Sotnikova L.V., PolenovaS.N., Mislavskaya N.A., PetrovA.M., BasovaM.M. SUSTAINABLE DeVElOPMENT, MACRO AND MICRO LEVEL: RUSSIAN AND FOREIGN MODEL / International Journal of Recent Technology and Engineering. 2019. T. 8. № 2. C. 4524-4532.

12. Kosolapova M.V., Muravitskaya N.K., Tolmachev M. N., Melnikova L.A., PetrovA.M. TECHNOLOGY FOR SOLVING THE PROBLEMS RELATED TO THE IMPLEMENTATION OF THE CONCEPT OF PRESERVING CAPITAL IN ACCOUNTING AND STATISTICS / International Journal of Recent Technology and Engineering. 2019. T. 8. № 3. C. 789-792.

13. Kosolapova M.V., PetrovA.M., YshanovI.G., Muravitskaya N.K., NurmuhamedovaH.S. THE ECONOMIC SIGNIFICANCE OF STATISTICAL RESEARCH ACTIVITIES OF REPRESENTATIVE OFFICES OF COMPANIES ABROAD / International Journal of Innovative Technology and Exploring Engineering. 2019. T. 8. № 10. C. 27132722.

14. Petrov A.M., Yurasova I. O., Putihin Y.E., Poluleh M. V., Erohina V.N. ACCOUNTANT MODELING TECHNOLOGY AND STATISTICS IN THE CONTEXT OF THE NEW EDUCATIONAL CONCEPT / International Journal of Innovative Technology and Exploring Engineering. 2019. T. 8. № 12. C. 3214-3217.

15. Petrov A.M., Kiseleva N.P., Kevorkova Z.A., Melnikova L.A., YshanovI.G. PRESENT DEVELOPMENT PRACTICES FOR TAX, FINANCIAL AND STATISTICAL REPORTING IN THE RUSSIAN FEDERATION / International Journal of Innovative Technology and Exploring Engineering. 2019. T. 8. № 12. C. 3538-3542.

16. Karpova T.P., Petrov A.M., Antonova O.V. DIRECTIONS OF ACCOUNTING DEVELOPMENT IN THE CONDITIONS OF DIGITALIZATION / Journal of Advanced Research in Dynamical and Control Systems. 2018. T. 10. № 7 Special Issue. C. $117-125$

17. Lymar M.P., Kevorkova Z.A., Petrov A. M.THE CONVERGENCE OF NATIONAL AND INTERNATIONAL ACCOUNTING STANDARDS: CHINESE EXPERIENCE / International Journal of Civil Engineering and Technology. 2018. T. 9. № 13. C. 82-94.

18. Бабаев Ю.А., Друцкая М. В., Кеворкова Ж. А., Листопад Е. Е., Петров А. М. БУХГАЛТЕРСКИЙ УЧЕТ, АНАЛИЗ И АУДИТ ВНЕШНЕЭКОНОМИЧЕСКОЙ ДЕЯТЕЛЬНОСТИ / учебник для студентов обучающихся по специальности 080109 «Бухгалтерский учет, анализ и аудит» / под редакцией Ю.А. Бабаева. Москва, 2010.

19. Петров А.М., ПолоУс Е.А. ПОВЫШЕНИЕ ТРАНСПАРЕНТНОСТИ ПОКАЗАТЕЛЯ ДЕБИТОРСКОЙ ЗАДОЛЖЕННОСТИ В ОТЧЕТНОСТИ / Международный бухгалтерский учет. 2011. № 6 (156). С. 2-12. 
20. Карпова Т.П., Петров А. М., Горбаткова Г. А., Самарина Л. Б., Дашкина Г. Г., Сидорова М. И., Сабанин Р. Л., Ситникова В.А., Листопад Е.Е. БУХГАЛТЕРСКИЙ УЧЕТ В СФЕРЕ УСЛУГ / учебник дЛя студентов высшего профессионального образования, обучающихся по специальности 080109 «Бухгалтерский учет, анализ и аудит» / Под редакцией М.А. Вахрушиной; Москва, 2011. Сер. Читай

21. Петров А.М., МельнИковаЛ.А. ФОРМИРОВАНИЕ ОТЧЕТНОСТИ В СООТВЕТСТВИИ С ТРЕБОВАНИЯМИ МСФО КАК ОБЪЕКТИВНАЯ НЕОБХОДИМОСТЬ НА СОВРЕМЕННОМ ЭТАПЕ РАЗВИТИЯ ЭКОНОМИКИ РФ / Проблемы современной экономики. 2017. № 2 (62). С. 105-107.

22. ТЕОРИЯ БУХГАЛТЕРСКОГО УЧЕТА / учебник / Ю.А.Бабаев, А. М.Петров; под ред. Ю.А.Бабаева. Москва, Проспект, 2011. (Изд. 5-е, перераб. и доп.)

23. Зарегистрировано преступлений по ст. 285 - злоупотребление должностными полномочиями: Динамика // Информационно-аналитический портал правовой статистики Генеральной прокуратуры Российской Федерации.-Текст: электронный._URL: http://crimestat.ru/offenses_chart. 